\title{
AS REPERCUSSÕES DA PANDEMIA DE COVID-19 NO TURISMO DOS PRINCIPAIS DESTINOS DO RIO GRANDE DO NORTE
}

\author{
THE REPERCUSSIONS OF THE COVID-19 PANDEMIC IN TOURISM IN THE MAIN DESTINATIONS OF RIO GRANDE DO \\ NORTE
}

\section{LAS REPERCUSIONES DE LA PANDEMIA COVID-19 EN EL TURISMO DE LOS PRINCIPALES DESTINOS DE RIO GRANDE DO NORTE}

\section{RESUMO}

O ano de 2020 vivenciou uma crise histórica, desencadeada pela pandemia de Covid-19. O turismo está entre as atividades econômicas mais atingidas pela crise e sendo o estado do Rio Grande do Norte (RN) um importante destino turístico brasileiro, o presente artigo tem por objetivo analisar as repercussões desta crise no setor de turismo dos principais destinos do RN, ao longo do ano de 2020 . A pesquisa é de natureza exploratória e explicativa, com análise qualitativa e quantitativa de dados primários e secundários. Os resultados mostram que o ano de 2020 pode ser dividido em dois diferentes momentos: o primeiro se refere ao 10 semestre de 2020, período de acirramento da crise, com altas taxas de desemprego no setor e dependência dos trabalhadores autônomos e informais das redes de solidariedade e das políticas de seguridade social; o segundo momento se refere à retomada do turismo regional/rodoviário a partir de julho de 2020 e, posteriormente do turismo nacional/aéreo, que reaquece o mercado de trabalho do setor, mesmo ainda em tempos de pandemia.

Palavras-chave: Covid-19. Turismo. Natal/RN. Tibau do Sul/RN. São Miguel do Gostoso/RN.

\section{ABSTRACT}

The year 2020 experienced a historic crisis, triggered by the Covid-19 pandemic. Tourism is among the economic activities most affected by the crisis and the state of Rio Grande do Norte (RN) being an important Brazilian tourist destination, the present article aims to analyze the repercussions of this crisis in the tourism sector of the main destinations of RN, throughout the year 2020. The research is exploratory and explanatory in nature, with qualitative and quantitative analysis of primary and secondary data. The results show that the year 2020 can be divided into two different moments: the first refers to the 1st semester of 2020, a period of worsening of the crisis, with high unemployment rates in the sector and dependence on self-employed and informal workers in solidarity networks. and social security policies; the second moment refers to the resumption of regional/road tourism as of July 2020 and, later, national/air tourism, which reheated the sector's labor market, even in times of pandemic.

Keywords: Covid-19. Tourism. Natal/RN. Tibau do Sul/RN. São Miguel do Gostoso/RN.

\section{RESUMEN}

El año 2020 experimentó una crisis histórica, desencadenada por la pandemia de Covid-19. El turismo se encuentra entre las actividades económicas más afectadas por la crisis y siendo el estado de Rio Grande do Norte (RN) un importante destino turístico brasileño, el presente artículo tiene como objetivo analizar las repercusiones de esta crisis en el sector turístico de los principales destinos de RN, durante todo el año 2020. La investigación es de carácter exploratorio y explicativo, con análisis cualitativo y cuantitativo de datos primarios y secundarios. Los resultados muestran que el año 2020 se puede dividir en dos momentos diferenciados: el primero se refiere al 1er semestre de 2020, un período de agravamiento de la crisis, con altas tasas de desempleo en el sector y dependencia de autónomos e informales en redes de solidaridad y políticas de seguridad social; el segundo momento se refiere a la reanudación del turismo regional/por carretera
(D) Carolina Todesco ${ }^{a}$

(D) Maria Aparecida Pontes da Fonseca ${ }^{\text {a }}$

(D) Itamara Lúcia da Fonseca a (D) Fernanda Raphaela Alves Dantas $^{\text {a }}$

a Universidade Federal do Rio Grande do Norte (UFRN), Natal, RN, Brasil

DOI: $10.12957 /$ geouerj.2021.61317

Correpondência: caroltodesco@gmail.com

Recebido em: 17 mar. 2021 Aceito em: 27 jun.2021 
a partir de julio de 2020 y, posteriormente, al turismo nacional/aéreo, que recalentó el mercado laboral del sector, incluso en tiempos de pandemia.

Palabras-clave: Covid-19. Turismo. Natal/RN. Tibau do Sul/RN. São Miguel do Gostoso/RN. 


\section{INTRODUÇÃO}

Considerando que o ano de 2020 vivenciou uma das piores crises sanitárias, sociais e econômicas do século XXI, com rebatimentos diretos no setor de turismo, e sendo o estado do Rio Grande do Norte (RN) um importante destino turístico brasileiro, onde essa atividade assume um papel relevante na economia, tornase necessário avaliar as repercussões e a magnitude com que a pandemia de Covid-19 afetou os lugares, as atividades econômicas, bem como os trabalhadores formais e informais do turismo.

No estado do Rio Grande do Norte, o principal destino turístico é a capital, o município de Natal. Antes da pandemia, em dezembro de 2019 e janeiro de 2020, conforme pesquisa do Ministério do Turismo (BRASIL, 2019b), Natal ficou em segundo lugar no ranking de destinos de viagens nacionais mais procurados do Brasil. Tibau do Sul, conhecido pela famosa Praia de Pipa, é o segundo destino de maior destaque do estado, situado a $72 \mathrm{~km}$ ao sul da capital. O terceiro destino mais procurado do estado é o município de São Miguel do Gostoso (BRASIL, 2019a), localizado no litoral a $102 \mathrm{~km}$ ao norte de Natal.

Os três municípios têm em comum a exploração do turismo de sol e mar, mas os dados constitutivos de cada território são expressivamente diferentes, principalmente em termos sociais e econômicos, o que significa que uma crise como a gerada pela pandemia de Covid-19 tem rebatimentos distintos em cada um desses lugares.

Desta forma, o objetivo geral do artigo é analisar as repercussões da pandemia de Covid-19 nos principais destinos turísticos do Rio Grande do Norte, ao longo do ano de 2020. Para isso, foi realizada uma pesquisa de natureza exploratória e explicativa, com uma abordagem qualitativa e quantitativa de dados primários e secundários.

O artigo, além da introdução, está estruturado em três partes: a primeira traz uma breve apresentação do cenário pandêmico e os efeitos no setor de turismo; a segunda parte detalha os procedimentos metodológicos adotados na pesquisa; e a terceira apresenta e discute os resultados do estudo realizado em Natal/RN, Tibau do Sul/RN e São Miguel do Gostoso/RN, analisando a retração e retomada dos fluxos de passageiros aéreos, o perfil das empresas características do turismo, o comportamento do mercado de trabalho formal e por fim, as estratégias de enfrentamento adotadas pelos trabalhadores autônomos e informais diante da crise.

\section{O cenário pandêmico e o setor de turismo}

O ano de 2019 foi um ano de crescimento do setor de turismo no mundo. Dados da WTTC (2020b) revelam que, naquele ano, o setor de viagens e turismo contribuiu com US\$ 8,9 trilhões para o PIB mundial, representando 10,3\% do PIB global, além de ser responsável por 1 a cada 10 empregos no mundo, totalizando 
330 milhões de empregos no setor. No Brasil, o setor de turismo, em 2019, representou 7,7\% do PIB, sendo responsável por 7,4 milhões de empregos (WTTC, 2020a). Entretanto, a realidade desse setor mudou drasticamente após o surgimento da Covid-19, em dezembro de 2019.

A China, por ter sido o epicentro da doença, isolou a cidade de Wuhan (metrópole de 11 milhões de habitantes), construiu hospitais temporários, estabeleceu a restrição da mobilidade nas cidades, fechou estações de trem e de ônibus, restringiu a circulação de veículos privados, proibiu a abertura do comércio, restaurantes e hotéis, suspendeu atividades acadêmicas e eventos, impôs o confinamento das pessoas em casa (quarentena), estabeleceu o uso obrigatório de máscaras e iniciou um controle rigoroso dos voos internacionais nos aeroportos do país, com aferição de temperatura de passageiros e até proibição da entrada de estrangeiros (WHO, 2020; KRAEMER et al., 2020).

Com a propagação da Covid-19 pelos cinco continentes, essas medidas, que antes pareciam extremadas, foram adotadas por inúmeros países e, em março de 2020, já fazia parte do cotidiano de $1 / 3$ da população mundial $(G 1,2020)$, mês em que a OMS eleva a contaminação causada pela Covid-19 ao status de pandemia. O modelo de restrição adotado por cada país, no entanto, vem dependendo do nível de disseminação da doença, das condições do sistema público de saúde, do contexto político e do alinhamento com as recomendações da Organização Mundial da Saúde.

As medidas de controle e contenção da pandemia de Covid-19 interferem significativamente nos diferentes momentos da produção, consumo, distribuição e reinvestimento do capital. E, como coloca Harvey (2020), com uma economia altamente globalizada, mesmo que a epidemia se concentrasse apenas na China, já teria efeitos significativos para a economia global. Ao adquirir status de pandemia, as dimensões da crise sanitária, social e econômica gerada pela Covid-19, tornam-se muito mais complexas e profundas, tendo em vista as "rivalidades geopolíticas, desenvolvimentos geográficos desiguais, instituições financeiras, políticas estatais, reconfigurações tecnológicas e uma rede em constante mudança das divisões do trabalho e das relações sociais" (HARVEY, 2020).

Topper e Lagadec, em 2013, com base no acidente nuclear em Fukushima, do furacão Katrina, da crise financeira de 2008 e dos protestos civis, elencaram algumas características das crises do século XXI: a. de larga escala para fora de escala: os principais eventos não são novos, mas se tornaram mais densos e parecem afetar um número maior de pessoas, por causa de apagões, pandemias, mudanças econômicas e implosões sociais. A multiplicação e a concomitância de tais megachoques levam a situações em que os meios são sobrecarregados, em que todo mundo ou quase está sob ameaça; b. da complexidade ao ilegível: os megachoques podem desencadear tremores impossíveis de categorizar e mapear; c. de fortemente

${ }^{1}$ Documento eletrônico não paginado. 
relacionadas a totalmente interdependentes: as dinâmicas de reverberação estão se desenrolando não apenas de um lugar para outro, mas de uma rede para outra, de um hub para outro, de um tecido subjacente para outro - local, nacional e globalmente; d. de alta velocidade à instantaneidade: em 2003, o SARS se desenvolveu de Hong Kong para Toronto em poucas horas e a capital de Ontário estava em crise profunda antes que as Organizações Mundiais de Saúde emitissem o alerta mundial; a cobertura da mídia eletrônica agora é totalmente em tempo real, globalmente; e. de eventos locais a deslocamentos profundos: devido às interdependências globais, as ondas de choque estão encontrando um ambiente favorável aos efeitos da cadeia instantânea sem 'compartimentos estanques', a crise moderna não se restringe a uma área política específica (por exemplo, saúde ou energia), pula de um campo para outro, desenterrando problemas e recombinando-os em mega-ameaças previstas (TOPPER; LAGADEC, 2013).

À época da publicação, Topper e Lagadec afirmaram que nenhuma crise ainda havia apresentado simultaneamente todos esses elementos, porém a crise da pandemia de Covid-19, segundo Schmidt et al. (2020), contemplou o panorama completo descrito pelos autores.

Como em crises anteriores, esta tem rebatimentos diferentes a depender do nível de vulnerabilidade em que se encontra cada porção do território. Nesse sentido, Alves (2020) ${ }^{2}$ assinala a situação do Brasil para o enfrentamento da atual crise:

\begin{abstract}
A pandemia da Covid-19 não poderia chegar ao Brasil em pior hora. A economia brasileira já estava enfraquecida, [...], com baixa produtividade, baixa competitividade internacional, baixo dinamismo na produção de bens e serviços, baixa geração de emprego decente, baixa geração de renda, baixo investimento e com "pressão alta" no déficit fiscal, na dívida pública e nos indicadores de pobreza e desigualdade social.
\end{abstract}

O cenário de crise, portanto, é grave, com rebatimentos em escala global, nacional, regional e local, em suas múltiplas dimensões - sanitárias, sociais, econômicas, ambientais e políticas, com resultados ainda imprevisíveis; todavia, após um ano de pandemia, alguns impactos já são nítidos e passíveis de análise.

O setor de turismo foi um dos primeiros afetados pelas medidas de combate à pandemia. Em abril de 2020, a Organização Mundial do Turismo (OMT) anunciou que mais de $96 \%$ de todos os destinos turísticos mundiais estavam fechados, e das regiões analisadas, 90 tinham suas fronteiras fechadas para turistas, enquanto 44 aceitavam visitantes de certos países (ONU NEWS, 2020a). Ainda segundo a OMT, entre janeiro e outubro de 2020 ocorreu uma redução de 900 milhões de turistas internacionais no mundo, gerando uma perda de US\$ 935 bilhões em receitas de exportação, mais de 10 vezes o prejuízo registrado em 2009, quando o mundo sofria o impacto da crise financeira (ONU NEWS, 2020b). Nesse sentido, Beni (2020, p. 3) destaca como o turismo é um setor sensível:

\footnotetext{
2 Documento eletrônico não paginado.
} 
O Turismo, mais do que qualquer outro setor da economia, apresenta uma característica de extrema sensibilidade a toda a alteração situacional sendo extremamente retrátil a oscilações de taxa de câmbio, flutuações sazonais da demanda, riscos meteorológicos, geológicos, convulsões sociais, instabilidade política, terrorismo e riscos epidêmicos e pandêmicos que comprometam a saúde pública, como o recente surto do COVID-19.

O acirramento das medidas restritivas acarretou o fechamento ou suspensão das atividades das empresas de turismo, e consequentemente, induziu a altas taxas de desemprego no setor. Em outubro de 2020, a Confederação Nacional do Comércio de Bens, Serviços e Turismo (CNC) anunciou que 49,9 mil empresas de turismo fecharam as portas de março a agosto, durante a pandemia, a maioria microempresas (29,2 mil empresas) e pequenas empresas (-19,1 mil empresas), representando a extinção de $16,7 \%$ do total de empresas de turismo no Brasil (VALOR, 2020).

A pandemia exigiu a adaptação da oferta dos produtos e serviços turísticos. Entretanto, é um enorme desafio pensar em turismo em tempos de distanciamento social e confinamento, tendo em vista que a atividade exige essencialmente deslocamentos espaciais e a presença do turista para a prestação de serviços. Segundo Barreto (2020), de uma lista extensa de serviços relacionados ao turismo, numa situação de pandemia, poucos podem ser prestados sem riscos, sejam para o prestador ou para o consumidor.

Dessa forma, atividades como meios de hospedagem, transportes, cruzeiros, guias de turismo, passeios turísticos, eventos, dentre outros, tiveram que ser paralisadas ou diminuíram significativamente, uma vez que esses serviços induzem à aglomeração de pessoas (BARRETO, 2020; MECCA; GEDOZ, 2020).

A paralisação do setor, de janeiro a julho de 2020 , resultou num saldo negativo de -364.044 postos de trabalho formais em turismo no Brasil, segundo o relatório de impacto da pandemia publicado pelo Ministério do Turismo (BRASIL, 2020b).

Além disso, cabe registrar que o emprego nas atividades econômicas do turismo, conforme Santos (2018, p. 120), é historicamente marcado por:

\footnotetext{
uma acentuada informalidade, sazonalidade e rotatividade tornando-se um dos grandes desafios do setor e que compromete os serviços oferecidos, em razão do emprego de uma força de trabalho com uma baixa escolaridade, baixa qualificação, baixa remuneração e que, portanto, convive com condições diárias de precariedade no trabalho. (grifo nosso)
}

A sazonalidade, uma das principais características do turismo, influi na produção de dois mercados de trabalho: um permanente, que contrata independente da época do ano, e um temporário, que contrata apenas em períodos de alta temporada (MELIANI, 2015).

De acordo com o Ipea (2019), o número de empregos informais do turismo, em dezembro de 2019, totalizou 1.123.115, número superior ao total de empregos formais, 1.069.120. A informalidade é puxada 
pelas regiões Norte e Nordeste, pois somente nessas duas regiões do país o número de empregos informais é maior que o número de empregos formais no setor turístico (IPEA, 2019).

Mesmo considerando que o trabalho informal contribui com aqueles que não conseguem oportunidades no mercado de trabalho formal, segundo Meliani (2012), a informalidade acarreta uma série de custos sociais aos lugares, como a perda de arrecadação pública, bem como aos trabalhadores, que ficam desamparados de direitos trabalhistas, gerando distanciamento da cidadania e alienação do trabalho. Para Cañada (2019), a precarização do trabalho no turismo é resultado de políticas empresariais e de apoio estatal que favorecem a flexibilidade e exploração da força de trabalho, traduzindo-se para a classe trabalhadora em condições de vulnerabilidade e fragilidade, com a oferta de salários baixos, empregos sazonais, longas jornadas de trabalho, que acabam por caracterizar as condições do trabalho informal no setor.

Sendo assim, a presente pesquisa tem como foco analisar as repercussões da crise gerada pela pandemia de Covid-19 não apenas nas empresas características do turismo e no mercado de trabalho formal, mas também revelar as condições em que os trabalhadores informais do turismo enfrentaram essa crise, nos principais destinos turísticos do estado do Rio Grande do Norte, isto é, Natal, Tibau do Sul e São Miguel do Gostoso.

\section{Metodologia}

A metodologia da pesquisa é de natureza exploratória e explicativa, com abordagem de análise quantitativa e qualitativa de informações e dados primários e secundários. Para a coleta de dados primários, foram realizadas 8 (oito) entrevistas semiestruturadas por videoconferência (plataforma Google Meet), no mês de dezembro de 2020, com representantes de órgãos oficiais de turismo municipais, entidades do trade turístico e sindicato de trabalhadores da área do turismo referentes ao recorte espacial em estudo, conforme quadro 1.

Quadro 1. Entidades entrevistadas na pesquisa de campo. Organizado pelas autoras (2021).

\begin{tabular}{|l|l|l|}
\hline \multicolumn{1}{|c|}{ Entidade } & \multicolumn{1}{|c|}{ Cargo do Entrevistado } & \multicolumn{1}{|c|}{ Data da Entrevista } \\
\hline Secretaria Municipal de Turismo do Natal & Secretária-Adjunta & $18 / 12 / 2020$ \\
\hline Secretaria Municipal de Turismo de Tibau do Sul & Secretária & $17 / 12 / 2020$ \\
\hline Secretaria Municipal de Turismo de São Miguel do Gostoso & Secretária & $15 / 12 / 2020$ \\
\hline Sindicato dos Guias de Turismo do Rio Grande do Norte & Diretora de Marketing & $7 / 12 / 2020$ \\
\hline $\begin{array}{l}\text { Sindicato dos Bugueiros do Rio Grande do Norte } \\
\text { (Sindbuggy-RN) }\end{array}$ & Presidente & $8 / 12 / 2020$ \\
\hline $\begin{array}{l}\text { Associação dos Quiosqueiros da Praia de Ponta Negra } \\
\text { (AQPN-RN) }\end{array}$ & Presidente & $8 / 12 / 2020$ \\
\hline Cooperativa 4x4 & Presidente & $15 / 12 / 2020$ \\
\hline Associação dos Ambulantes de Ponta Negra & Presidente & $16 / 12 / 2020$ \\
\hline
\end{tabular}


As principais fontes oficiais consultadas para o levantamento de dados sobre empregos e empresas características do turismo e fluxos aéreos foram: a Relação Anual de Informações Sociais (Rais) e o Cadastro Geral de Empregados e Desempregados (Caged), do Ministério da Economia; o Painel de Empresas do Sebrae, que disponibiliza dados da Receita Federal do Brasil (RFB); e a planilha de voos e operações aéreas dos aeroportos brasileiros, disponibilizada pela Agência Nacional da Aviação Civil (Anac).

Em relação ao recorte espacial, como mencionado, o estudo recai sobre Natal, Tibau do Sul e São Miguel do Gostoso (figura 1), que concentram os fluxos turísticos domésticos do estado do RN, de acordo com dados do Ministério do Turismo (BRASIL, 2019a).

Figura 1. Recorte espacial da pesquisa: Natal, Tibau do Sul e São Miguel do Gostoso

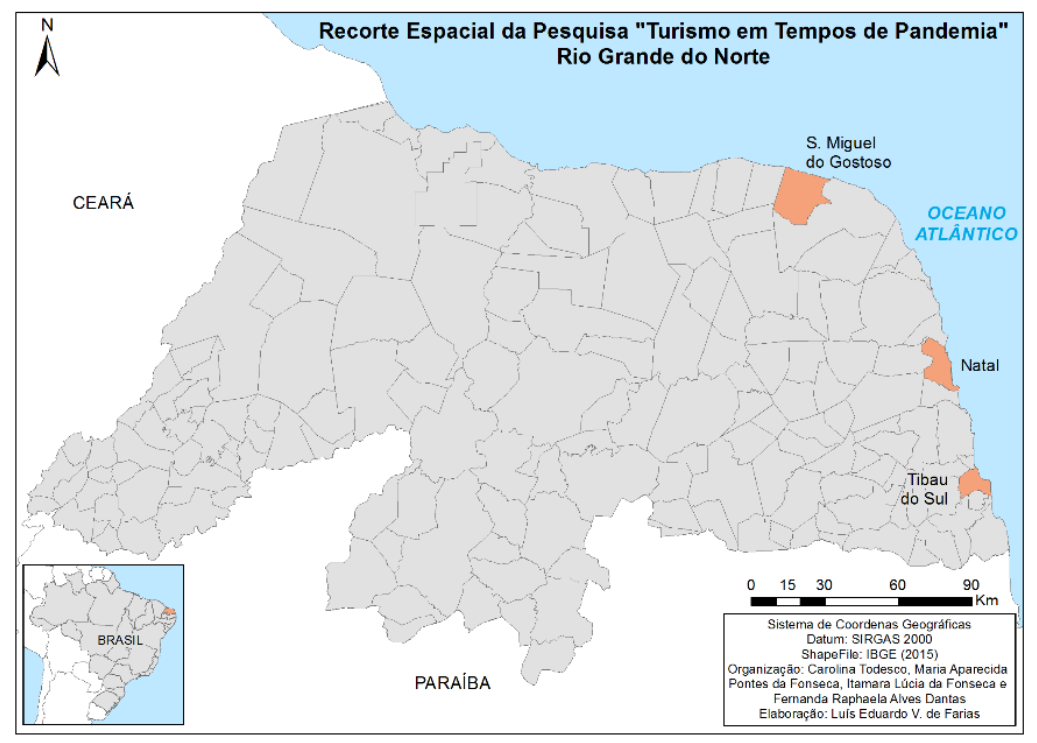

O recorte temporal do estudo refere-se ao ano de 2020; entretanto, para uma análise dos impactos da crise no setor de turismo, os dados de 2020 foram, quando possíveis, comparados aos dados do ano de 2019.

\section{Discussão dos resultados}

A queda e a retomada dos fluxos em 2020

No estado Rio Grande do Norte, o Aeroporto de São Gonçalo do Amarante, situado a 40 km do centro de Natal, é o principal portão de entrada de turistas nacionais e internacionais para os destinos em estudo.

A instantaneidade característica das crises do séc. XXI, como posto por Topper e Lagadec (2013), é perceptível ao se observar a queda dos fluxos aéreos. Pela planilha de voos disponibilizada pela Agência 
Nacional de Aviação Civil (Anac), é possível verificar que a partir de abril de 2020 o referido aeroporto teve todos os seus voos internacionais cancelados pelas companhias aéreas, não tendo sido retomados durante o resto do ano (figura 2). Cabe registrar que, de novembro de 2019 a fevereiro de 2020, o número de passageiros desembarcados em voos internacionais foi superior a 5 mil pessoas por mês, o que indica que a perspectiva era de crescimento do setor de turismo no estado, antes do reconhecimento da pandemia ${ }^{3}$.

Figura 2. Número de Passageiros de Voos Internacionais (desembarque) do Aeroporto de São Gonçalo do Amarante/RN. Fonte: Agência Nacional de Aviação Civil - ANAC. Organizado pelas autoras (2021)

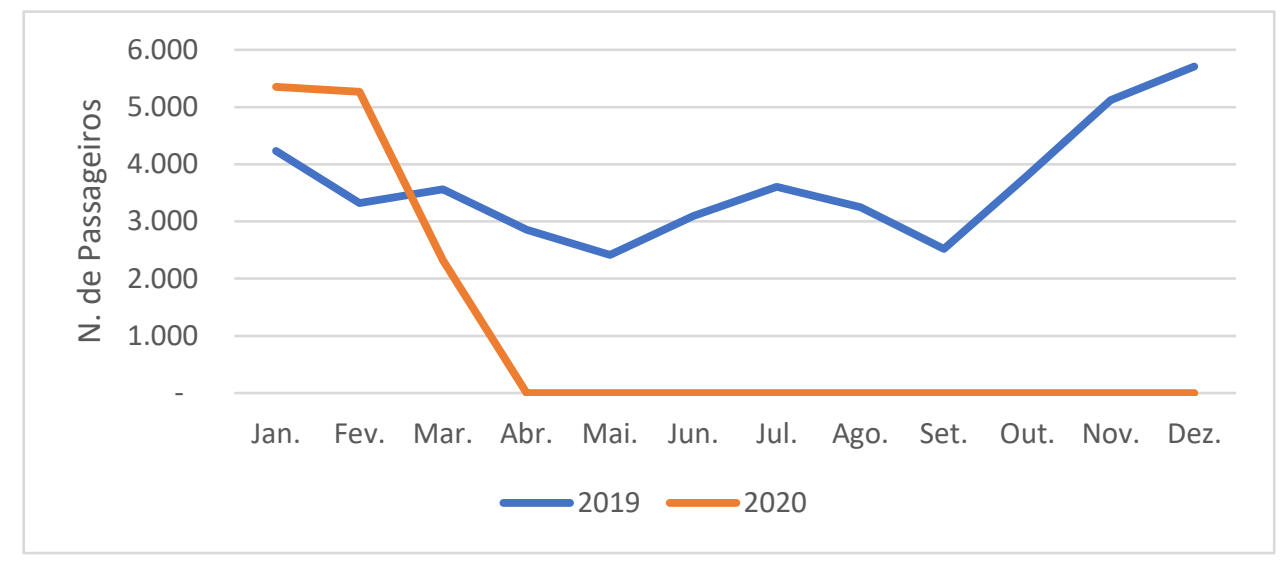

Diferentemente dos voos internacionais, os voos nacionais diminuíram, mas não cessaram, apresentando uma queda brusca do número de passageiros nos meses de abril, maio, junho e julho de 2020 (figura 3), uma média de -91\% comparada ao mesmo período de 2019, conforme dados da Anac (2020).

Figura 3. Número de Passageiros de Voos Domésticos (desembarque) do Aeroporto de São Gonçalo do Amarante/RN. Fonte: Agência Nacional de Aviação Civil - ANAC. Organizado pelas autoras (2021)

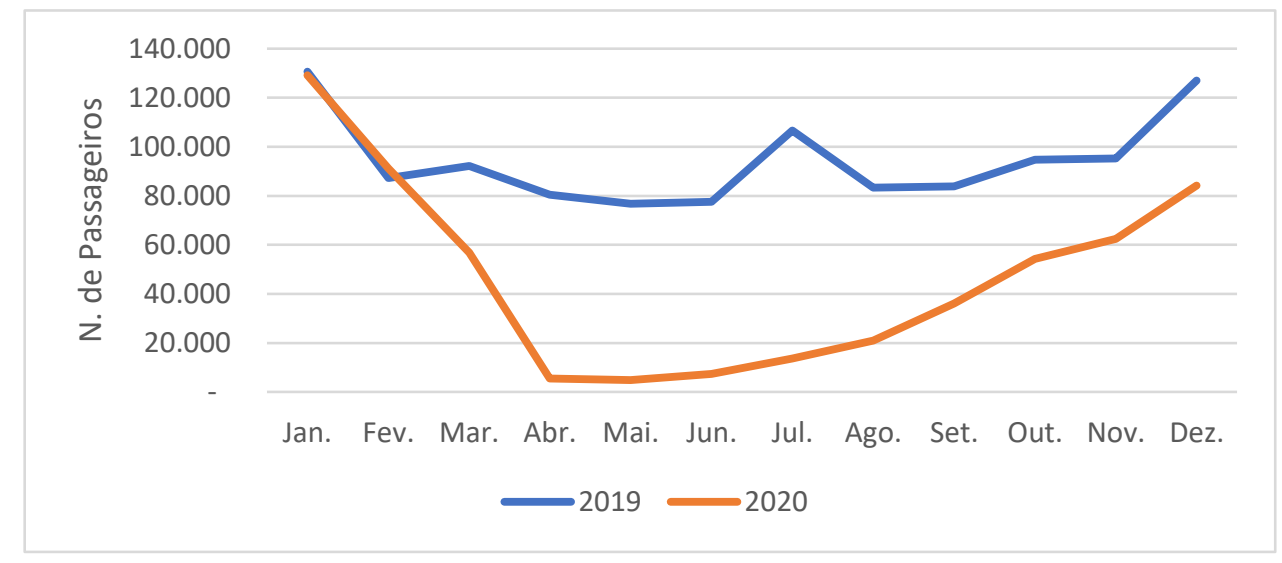

\footnotetext{
${ }^{3} \mathrm{~A}$ redução de impostos no querosene de aviação, pelo governo do estado do Rio Grande do Norte, por meio do Decreto estadual $n$. 28.934, de 18 de junho de 2019, contribuiu para promover o incremento de voos nacionais e internacionais para o Aeroporto Internacional de São Gonçalo do Amarante.
} 
O Aeroporto de São Gonçalo do Amarante/RN, no ano de 2020, comparado ao ano de 2019, teve uma redução de -50 \% dos fluxos nacionais (de 1.135 .774 para 566.288 ) e de $-70 \%$ dos fluxos internacionais (de 43.494 para 12.942), considerando somente o desembarque de passageiros (ANAC, 2020).

A figura 3, entretanto, sinaliza a retomada da atividade turística no estado do Rio Grande do Norte, especialmente a partir de setembro de 2020, mesmo ainda em tempos de pandemia. Esta situação revela que o turismo mesmo sendo uma atividade sensível a situações de insegurança (BENI, 2020), é capaz de se reinventar, readaptar e buscar novos nichos de mercado. Além disso, como ressalta Cruz (2020), o desejo reprimido de lazer à beira mar, após meses de confinamento, juntamente com o afrouxamento das medidas restritivas, trouxe à tona cenas do "velho normal" às praias brasileiras (como será visto mais adiante).

\section{O perfil das empresas características do turismo e o mercado de trabalho formal}

A queda nos fluxos aéreos assim como as medidas restritivas de circulação de pessoas e do funcionamento do comércio e serviços atingiram significativamente o setor de turismo nos destinos do Rio Grande do Norte, no primeiro semestre de 2020, mas o setor apresentou recuperação com a retomada dos fluxos turísticos no segundo semestre do ano.

Para compreender a dimensão da crise e a recuperação do turismo em Natal, Tibau do Sul e São Miguel do Gostoso, é preciso observar as características socioeconômicas, o perfil das empresas de turismo ${ }^{4}$ e a taxa de dependência do turismo de cada município.

A capital, Natal, tem uma população estimada de 890.480 hab. (IBGE, 2010) e apresenta um PIB concentrado no setor de serviços, que corresponde a $65 \%$ do total (IBGE, 2018). De acordo com dados da Receita Federal do Brasil, organizados e disponibilizados pelo Sebrae (2020), em 2020, o município tinha um total de 4.296 empresas características do turismo, considerando somente restaurantes e similares, hotéis, serviços de organização de feiras, congressos e exposições, agências de viagens, serviços de reserva, operadores turísticos e locação de automóvel (tabela 1). Esse conjunto de empresas foi responsável por gerar 5,2\% do emprego formal no município, em 2019, conforme dados obtidos na Relação Anual de Informações Sociais (Rais), do Ministério da Economia.

Em Natal, o maior número de empresas é representado por restaurantes e similares (1.928) e serviços de organização de feiras, congressos e exposições (962). Entretanto, as empresas que mais geram emprego

\footnotetext{
${ }^{4} \mathrm{O}$ perfil das empresas é definido por fatores como faturamento anual, número de empregados e atividades desempenhadas. $\mathrm{O}$ Microempreendedor Individual (MEI) surgiu para retirar da informalidade o empreendedor que trabalha por conta própria, sem sócios, seu faturamento não pode ser superior a R\$ 81 mil por ano ou R\$6.750 mil por mês (em média). A Microempresa (ME) deve apresentar receita bruta anual inferior ou igual a $\mathrm{R} \$ 360$ mil. Empresas com limite de faturamento anual de $\mathrm{R} \$ 4,8$ milhões podem ser enquadradas como Empresa de Pequeno Porte (EPP). Uma empresa de médio a grande porte não tem limite de faturamento ou tem receita bruta anual acima de $\mathrm{R} \$ 4,8$ milhões (SEBRAE, 2020).
} 
formal, em termos relativos, são os hotéis, seguidos pelos restaurantes e similares (tabela 1). Do total de empresas na área do turismo em Natal, 44\% são microempresas (ME) e 47\% são microempreendedores individuais (MEI), apenas $8 \%$ são pequenas a grandes empresas (SEBRAE, 2020).

No município de Natal, como se pode observar na tabela 1, o ano de 2020 fechou o mês de dezembro apresentando uma perda de -1.695 postos de trabalho, comparado ao mesmo mês de 2019 (cenário prépandemia). As empresas que mais demitiram funcionários, em termos absolutos, foram os hotéis (-885) e os restaurantes (-621), e, em termos relativos, foram as agências de viagens, que tiveram uma queda de $-26,4 \%$ dos postos de trabalho, seguidas pelos hotéis, com -19,8\%. Operadores turísticos e serviços de reserva são, em sua grande maioria, microempreendedores individuais, e empregam um número pouco expressivo, não tendo apresentado oscilação com a crise.

Tabela 1. Número de Empregos e Porte das Empresas Características do Turismo em Natal, Tibau do Sul e São Miguel do Gostoso $(2019 / 2020)$

\begin{tabular}{|c|c|c|c|c|c|c|c|c|c|}
\hline \multirow[b]{2}{*}{ Município } & \multirow[b]{2}{*}{ Subclasses CNAE } & \multicolumn{4}{|c|}{ EMPRESAS $^{1}$} & \multicolumn{4}{|c|}{ EMPREGOS } \\
\hline & & ME & MEI & $\begin{array}{c}\text { Pequeno a } \\
\text { Grande } \\
\text { Porte }\end{array}$ & $\begin{array}{c}\text { Total de } \\
\text { Empresa } \\
2020\end{array}$ & $\begin{array}{c}\text { N. de } \\
\text { Emprego }^{2} \\
\text { Dez. } 2019\end{array}$ & $\begin{array}{c}\text { N. de } \\
\text { Emprego }^{3} \\
\text { Dez. } 2020\end{array}$ & $\begin{array}{l}(2020)- \\
(2019)\end{array}$ & $\begin{array}{c}(2020)- \\
(2019) \%\end{array}$ \\
\hline \multirow{9}{*}{ Natal } & Restaurantes e Similares & 1.022 & 728 & 178 & 1.928 & 6.479 & 5.858 & -621 & $-9,6 \%$ \\
\hline & Serviços de Org. de Feiras... & 188 & 750 & 24 & 962 & 306 & 331 & 25 & $8,2 \%$ \\
\hline & Agência de Viagens & 225 & 208 & 33 & 466 & 580 & 427 & -153 & $-26,4 \%$ \\
\hline & Locação de Automóvel & 271 & 0 & 49 & 320 & 476 & 409 & -67 & $-14,1 \%$ \\
\hline & Operadores Turísticos & 17 & 240 & 3 & 260 & 43 & 50 & 7 & $16,3 \%$ \\
\hline & Hotéis & 152 & 0 & 90 & 242 & 4.480 & 3.595 & -885 & $-19,8 \%$ \\
\hline & Serviços de Reservas & 15 & 98 & 5 & 118 & 132 & 131 & -1 & $-0,8 \%$ \\
\hline & Total & 1.890 & 2.024 & 382 & 4.296 & 12.496 & 10801 & -1.695 & $-13,6 \%$ \\
\hline & Total (\%) & $44 \%$ & $47 \%$ & $8 \%$ & $100 \%$ & - & - & - & - \\
\hline \multirow{9}{*}{$\begin{array}{c}\text { Tibau do } \\
\text { Sul }\end{array}$} & Restaurantes e Similares & 189 & 71 & 15 & 275 & 618 & 619 & 1 & $0,2 \%$ \\
\hline & Hotéis & 129 & 0 & 43 & 172 & 1.084 & 1.053 & -31 & $-2,9 \%$ \\
\hline & Agência de Viagens & 13 & 35 & 3 & 51 & 16 & 20 & 4 & $25,0 \%$ \\
\hline & Serviços de Reservas & 5 & 16 & 1 & 22 & 8 & 9 & 1 & $12,5 \%$ \\
\hline & Operadores Turísticos & 3 & 11 & 0 & 14 & 8 & 7 & -1 & $-12,5 \%$ \\
\hline & Locação de Automóvel & 10 & 0 & 1 & 11 & 4 & 3 & -1 & $-25,0 \%$ \\
\hline & Serviços de Org. de Feiras... & 2 & 7 & 1 & 10 & 5 & 41 & 36 & $720,0 \%$ \\
\hline & Total & 351 & 140 & 64 & 555 & 1.743 & 1.752 & 9 & $0,5 \%$ \\
\hline & Total (\%) & $63 \%$ & $25 \%$ & $12 \%$ & $100 \%$ & - & - & - & - \\
\hline \multirow{9}{*}{$\begin{array}{l}\text { São Miguel } \\
\text { do Gostoso }\end{array}$} & Restaurantes e Similares & 40 & 21 & 4 & 65 & 70 & 58 & -12 & $-17 \%$ \\
\hline & Hotéis & 53 & 0 & 7 & 60 & 188 & 205 & 17 & $9 \%$ \\
\hline & Agência de Viagens & 6 & 7 & 0 & 13 & 2 & 1 & -1 & $-50 \%$ \\
\hline & Serviços de Org. de Feiras... & 2 & 6 & 0 & 8 & 0 & 0 & 0 & \\
\hline & Operadores Turísticos & 0 & 3 & 1 & 4 & 1 & 3 & 2 & $200 \%$ \\
\hline & Serviços de Reservas & 0 & 1 & 0 & 1 & 0 & 0 & 0 & \\
\hline & Locação de Automóvel & 1 & 0 & 0 & 1 & 0 & 0 & 0 & \\
\hline & Total & 102 & 38 & 12 & 152 & 261 & 267 & 6 & $2 \%$ \\
\hline & Total (\%) & $67 \%$ & $25 \%$ & $8 \%$ & $100 \%$ & - & - & - & - \\
\hline
\end{tabular}

Fontes: 'Sebrae, DataSebrae, Painéis de Empresas, (situação em 11 mar. 2020).

${ }^{2}$ Brasil, Ministério da Economia, Secretaria Especial de Previdência e Trabalho, RAIS, 2019.

${ }^{3}$ Brasil, Ministério da Economia, Secretaria Especial de Previdência e Trabalho, Novo Caged, 2020.

Nota: ME - Microempresa; MEI - Microempreendedor Individual.

Organizado pelas autoras (2021). 
$\mathrm{O}$ ano poderia ter fechado com números de desemprego ainda piores se não fosse a retomada do turismo, por volta de setembro, no município, que impulsionou novamente a contratação, especialmente pelos hotéis e restaurantes, nos últimos quatro meses do ano, como se pode observar na figura 4.

Figura 4. Número de trabalhadores admitidos e demitidos nos Hotéis e Restaurantes e Similares, no município de Natal, nos meses de 2020. Fonte: Brasil, Ministério da Economia, Secretaria Especial de Previdência e Trabalho, Novo Caged, 2020. Organizado pelas autoras (2021)
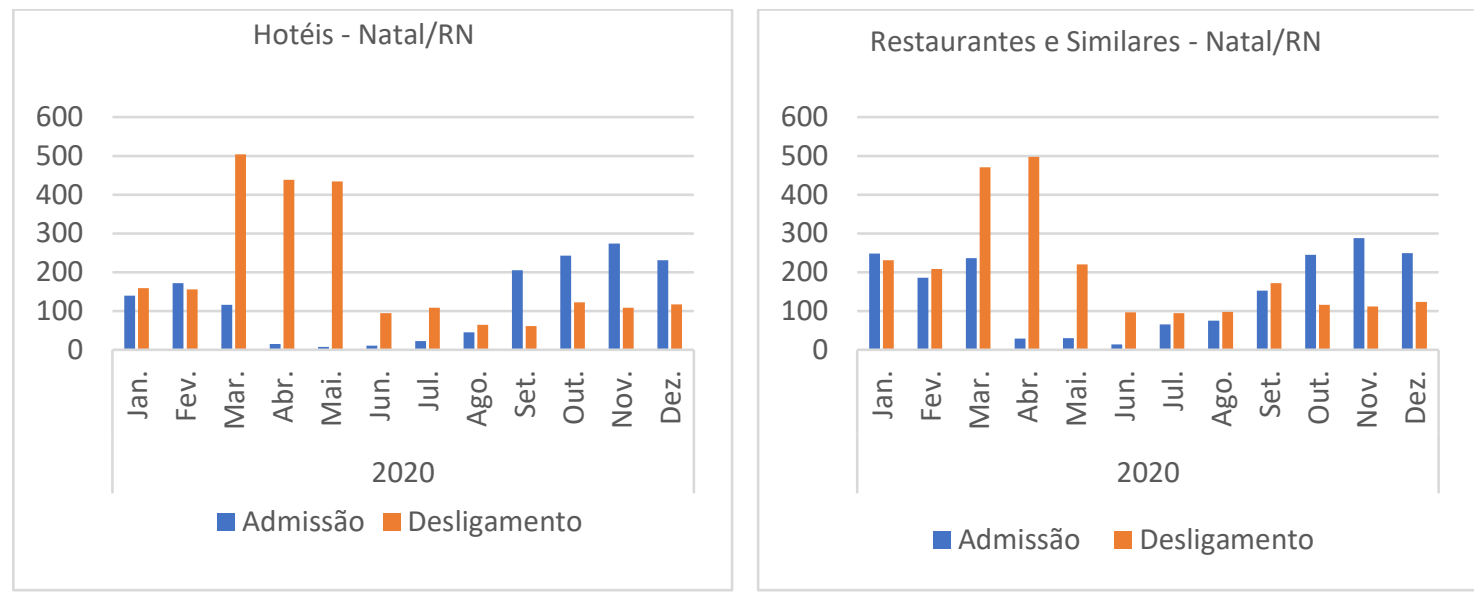

Nesse contexto, cabe registrar que Natal ficou em primeiro lugar no ranking de destinos mais procurados pelas viagens nacionais do Brasil, para o período de dezembro de 2020 e janeiro de 2021, segundo sondagem do Ministério do Turismo, realizada junto às operadoras e agências de viagens (BRASIL, 2020a).

Todavia, a recuperação do mercado de trabalho, ainda no ano de 2020 , em Tibau do Sul, foi mais expressiva que em Natal. O referido município tem uma população estimada de 14.440 hab. (IBGE, 2010), o setor de serviços equivale a 44\% do PIB (IBGE, 2018), e em 2019 as empresas do setor de turismo, elencadas na tabela 1, foram responsáveis por empregar $49 \%$ da população ocupada, conforme dados obtidos na Rais o que indica uma alta dependência econômica do turismo.

Tibau do Sul, em 2020, dispunha de 555 empresas da área do turismo, sendo 63\% microempresas e 25\% microempreendedores individuais. Grande parte das empresas de turismo são restaurantes e similares (275) e hotéis (172), também os principais geradores de emprego formal; juntos, em dezembro de 2019, geraram 1.702 empregos (97\% do total de empregos no setor). De março a junho de 2020 , essas duas atividades apresentaram altas taxas de desemprego, como se pode observar na figura 5. 
Figura 5. Número de trabalhadores admitidos e demitidos nos Hotéis e Restaurantes e Similares, no município de Tibau do Sul, nos meses de 2020. Fonte: Brasil, Ministério da Economia, Secretaria Especial de Previdência e Trabalho, Novo Caged, 2020. Organizado pelas autoras (2021)
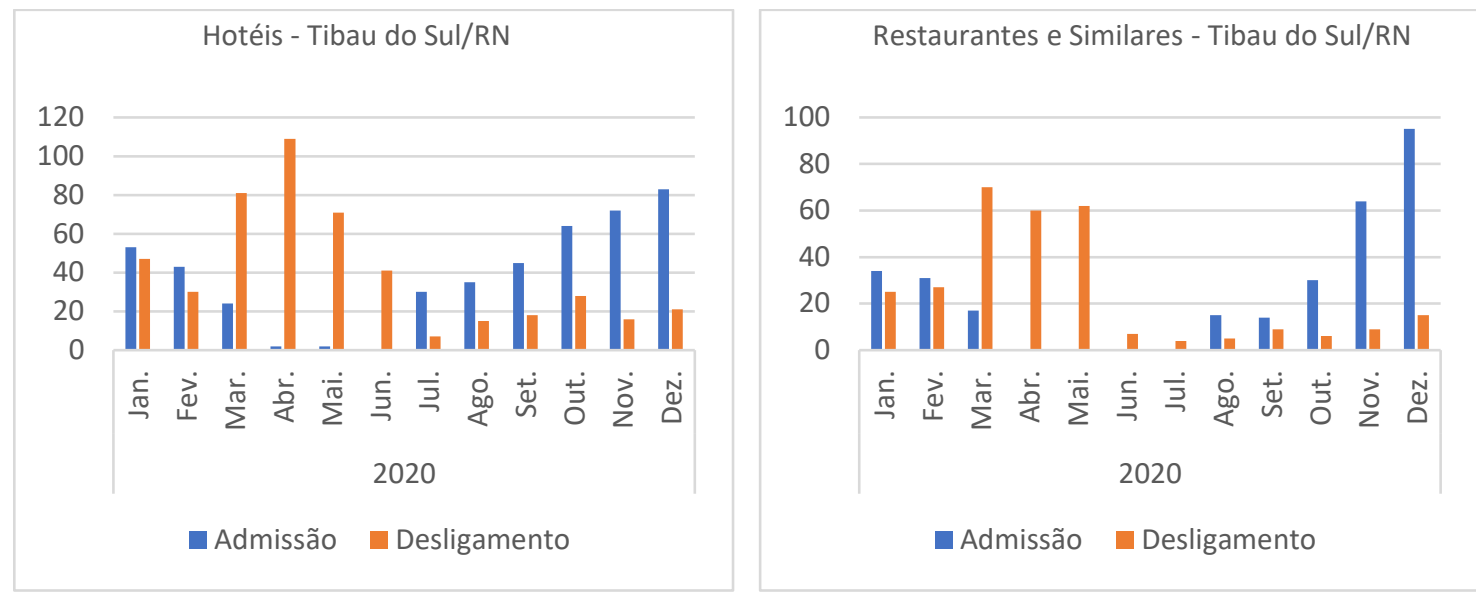

Com a retomada do turismo em Tibau do Sul, a partir de julho, as empresas reiniciaram a contratação (figura 5), o que acabou fechando o ano de 2020 de forma surpreendente, com um percentual de $0,5 \%$ a mais que em dezembro de 2019 (tabela 1).

Conforme a Secretária de Turismo de Tibau do Sul (2020), a retomada dos fluxos turísticos no município foi acima do esperado:

Na verdade, houve um fluxo maior do que o esperado na volta, nós tivemos o 7 de setembro melhor dos últimos 10 anos, maior do que os nossos réveillons, para você ter ideia nós esperávamos que íamos reabrir em julho e teoricamente seria uma baixa, mas nós tivemos média alta e agora tu vais nesse momento para Pipa e as ruas estão cheias. [...] o turista ele veio abraçar o mundo em 24 horas, é o mesmo jovem que vinha antes, porém triplicado muito mais do que antes, a gente não esperava.

Como coloca Cruz (2020), o "grito de independência dos turistas", amontoados nas praias, sem apresentarem preocupação com a pandemia, parece ter dado ao turismo a chave para um mundo paralelo, entre realidade e fantasia, onde o bom senso padece.

A retomada intensa do fluxo turístico no município, em meio à pandemia, repercutiu e foi notícia no G1 RN (2020b) sob o título "Turistas se aglomeram sem máscaras na praia da Pipa durante feriadão" (figura 6).

Figura 6. Centro de Pipa, em Tibau do Sul, noite de 06 de setembro de 2020. Foto: G1 RN, 2020b

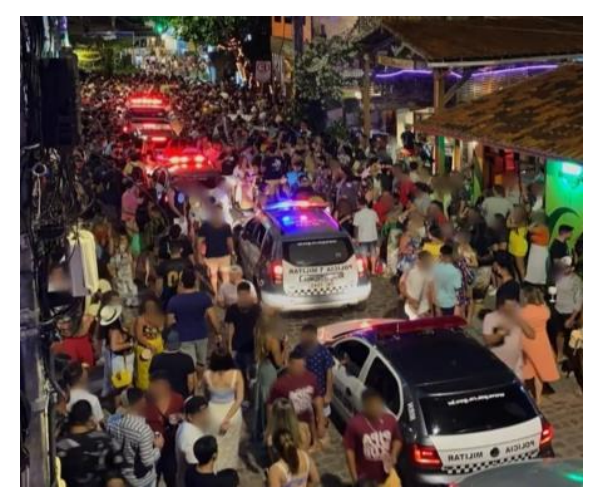


As cenas de ruas lotadas e turistas sem máscaras voltaram a ocorrer no referido destino, assim como em vários outros destinos litorâneos do país, o que leva a reflexões sobre o comportamento do turista em tempos de pandemia e a questionamentos sobre a existência ou não de um "novo normal" nos hábitos de viagens dos brasileiros, temas que estão sendo alvo de pesquisas acadêmicas e de órgãos oficiais de turismo ${ }^{5}$.

O município de São Miguel do Gostoso, dos três em estudo, é o menor em termos populacionais; de acordo com o IBGE (2010), tem uma população estimada de 10.632 hab. O setor de serviços corresponde apenas a 19\% do total do PIB (IBGE, 2018), porém as atividades características do turismo, elencadas na tabela 1, em 2019 , foram responsáveis por $31 \%$ da população empregada, demonstrando a importância do turismo na geração de emprego formal no município. Em 2020, São Miguel do Gostoso apresentava 152 empresas no setor de turismo, sendo a grande maioria microempresas (67\%), seguidas por microempreendedores individuais (25\%). No município, não há muita diversidade de empresas no setor, os restaurantes e os hotéis, juntos, correspondem a $82 \%$ do total de empresas e a $99 \%$ dos empregos formais (tabela 1 ).

No auge da crise, como se pode observar na figura 7, o saldo entre admissão e demissão foram negativos nos meses de março a julho no setor hoteleiro e de fevereiro a agosto de 2020 no setor de restaurantes e similares.

Figura 7. Número de trabalhadores admitidos e demitidos nos Hotéis e Restaurantes e Similares, no município de São Miguel do Gostoso, nos meses de 2020. Fonte: Brasil, Ministério da Economia, Secretaria Especial de Previdência e Trabalho, Novo Caged, 2020. Organizado pelas autoras (2021)
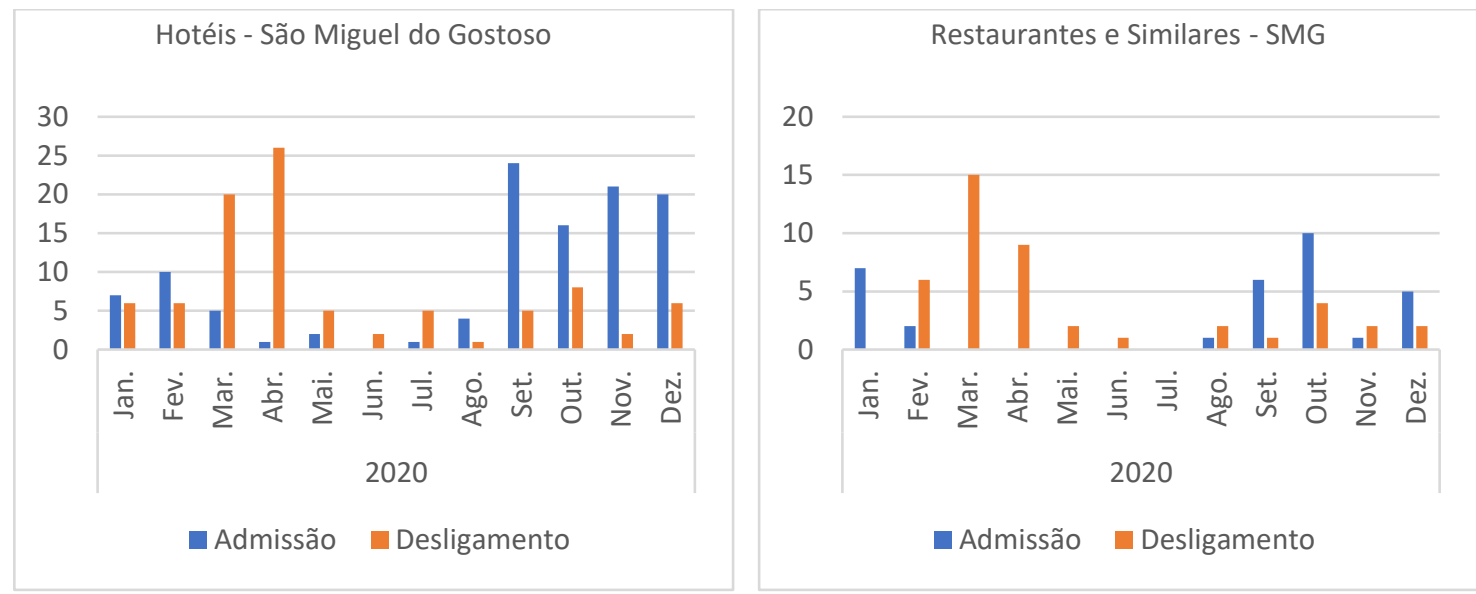

Em entrevista, a Secretária de Turismo de São Miguel do Gostoso (2020) relata o impacto da pandemia no primeiro semestre de 2020 no município:

[...] fomos a segunda cidade da região inteira a fechar literalmente, nós iniciamos no dia 25 de março com o trabalho de barreira sanitária aqui do nosso município, e foi realmente do dia 25 de março a 16

\footnotetext{
${ }^{5}$ Pesquisas nesse tema estão sendo realizadas pelos Observatórios de Turismo, pelo Ministério do Turismo, como também pelo Grupo de Pesquisa Turismo em Tempos de Pandemia: uma análise multi e trans escalar.
} 
de julho [...] que foi quando nós reabrimos a cidade e ao longo desses meses nós tivemos é claro o impacto nos meios de hospedagens e nos restaurantes, nos bares e nos passeios, gigantescos. São Miguel do Gostoso vive literalmente do turismo, isso causou realmente um transtorno econômico muito grande para a cidade.

Todavia, o cenário altera-se significativamente com a retomada do turismo no segundo semestre. No caso dos hotéis, o saldo positivo entre admitidos e demitidos inicia-se em agosto de 2020 e para restaurantes e similares em setembro (figura 7). Em dezembro de 2020, o número de trabalhadores formais do setor chega a ultrapassar o número registrado em dezembro de 2019 , demonstrando o aquecimento do mercado de trabalho com o retorno dos fluxos turísticos.

Conforme entrevista com as secretarias municipais de turismo das três destinações, primeiramente foi retomado o turismo regional/rodoviário, posteriormente o turismo nacional/aéreo, e o turismo internacional não retornou desde março de 2020.

Como visto, nos três municípios, Natal, Tibau do Sul e São Miguel do Gostoso, entre as atividades destacadas por Barreto (2020), Mecca e Gedoz (2020) como serviços que induzem aglomeração de pessoas e consequentemente tiveram que ser paralisadas ou diminuídas significativamente, o setor de meios de hospedagem e de restaurantes e similares foram os que mais sentiram os efeitos das medidas restritivas, nos primeiros meses da pandemia, mas assim que as medidas foram sendo flexibilizadas o mercado de trabalho reaqueceu novamente, acompanhando o retorno do turismo.

\section{O trabalhador autônomo e informal do turismo no contexto da crise: estratégias de sobrevivência}

Para aprofundarmos a análise a respeito das repercussões da crise sanitária no mercado de trabalho do turismo potiguar, recorremos a uma pesquisa de natureza qualitativa, contemplando entrevistas com entidades representativas dos trabalhadores que vivem do turismo, tais como: Associação de Ambulantes de Ponta Negra, Associação de Guia de Turismo do RN, Associação de Bugueiros do RN e Cooperativa 4x4 de passeios turísticos do litoral sul do estado.

Os decretos municipais e estaduais que determinavam somente o funcionamento de estabelecimentos comerciais e serviços essenciais para a população afetaram fortemente a atividade turística, particularmente a classe de trabalhadores que tinha sua sobrevivência associada aos passeios turísticos, tais como os guias de turismo, os bugueiros e os condutores de veículos $4 \times 4$. Os trabalhadores informais dos quiosques, bem como os ambulantes que trabalhavam na praia de Ponta Negra, uma das principais praias de Natal/RN, vendendo os mais diversos tipos de produtos, foram os mais impactados pela crise do setor, devido à sua condição de maior vulnerabilidade. 
A partir de final de junho de 2020 , as atividades foram retomadas paulatinamente com a publicação de decretos de reabertura, estabelecendo os protocolos de segurança. O quadro 2 apresenta o período da suspensão das atividades, como também da retomada, conforme os decretos municipais e estaduais.

Quadro 2. Decretos determinando suspensão e reabertura dos estabelecimentos comerciais e de serviços. Organizado pelas autoras (2021)

\begin{tabular}{|l|c|l|c|l|}
\hline $\begin{array}{c}\text { Município/ } \\
\text { Estado }\end{array}$ & $\begin{array}{c}\text { Data do decreto } \\
\text { de suspensão das } \\
\text { atividades }\end{array}$ & $\begin{array}{c}\text { N. do decreto } \\
\text { suspensão das } \\
\text { atividades }\end{array}$ & $\begin{array}{c}\text { Data do decreto de } \\
\text { reabertura das } \\
\text { atividades }\end{array}$ & $\begin{array}{c}\text { N. do decreto de } \\
\text { reabertura das } \\
\text { atividades }\end{array}$ \\
\hline Governo do RN & $20 / 03 / 2020$ & Decreto n. 29.541 & $\begin{array}{c}30 / 06 / 2020 \\
07 / 07 / 2020\end{array}$ & $\begin{array}{l}\text { Decreto n. } 29.794 \\
\text { Decreto n. } 29.815\end{array}$ \\
\hline Natal & $17 / 03 / 2020$ & Decreto n. 11.920 & $29 / 06 / 2020$ & Decreto n. 11.920 \\
\hline Tibau do Sul & $23 / 03 / 2020$ & Decreto n. 15 & $06 / 07 / 2020$ & Decreto n. 38 \\
\hline $\begin{array}{l}\text { São Miguel do } \\
\text { Gostoso }\end{array}$ & $24 / 03 / 2020$ & Decreto n. 75 & $\begin{array}{l}15 / 04 / 2020 \\
31 / 07 / 2020\end{array}$ & $\begin{array}{l}\text { Decreto n. } 84 \\
\text { Decreto n. } 100\end{array}$ \\
\hline
\end{tabular}

Com a ausência dos turistas, de março a junho, inclusive de moradores que deixaram de frequentar as praias, conforme registro das imagens a seguir, os estabelecimentos que atendiam esse público encerraram temporariamente suas atividades. Os referidos decretos perduraram por cerca de 5 meses e gradativamente os estabelecimentos foram retomando as atividades, adotando os protocolos de segurança, a partir do final de julho de 2020.

Figura 8. Praia de Ponta Negra/Natal, no período de isolamento social (abr./ 2020). Fotos: Maria Aparecida Pontes da Fonseca (2020)
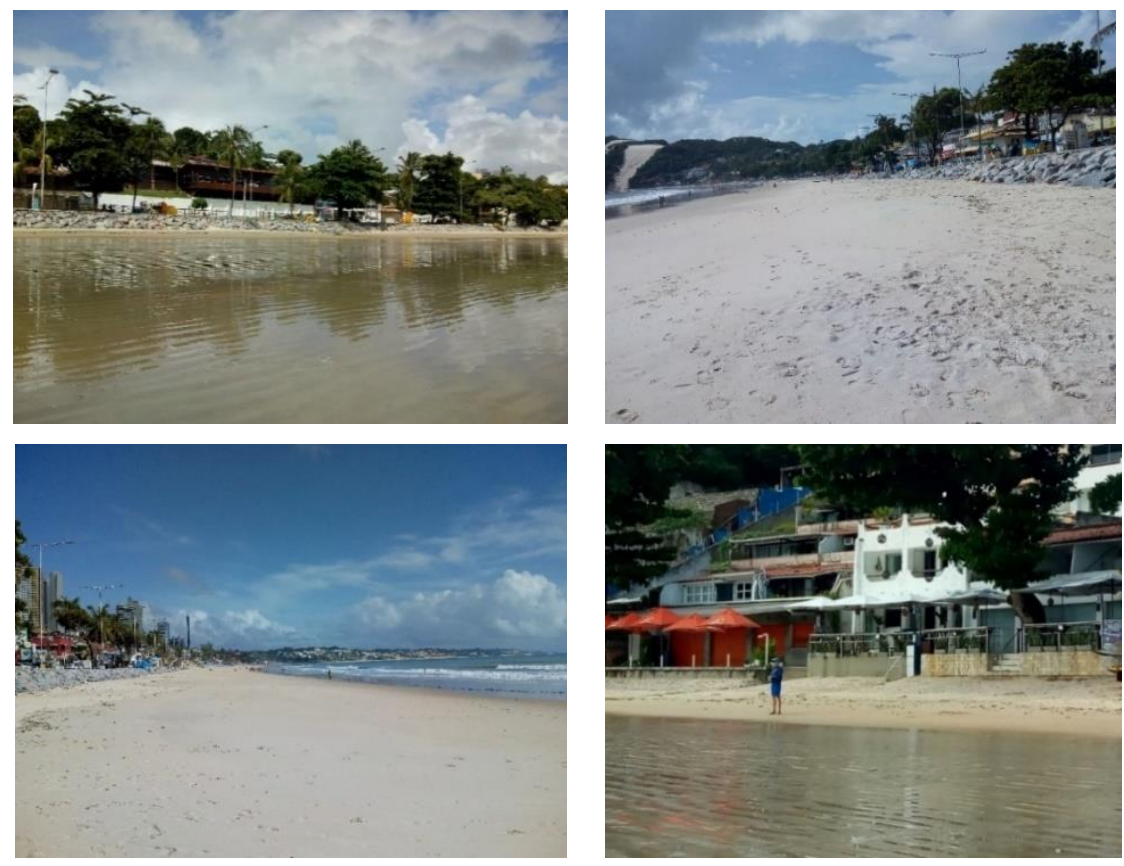
A avaliação do impacto da crise no setor de turismo por parte das entidades que fizeram parte do estudo foi definida como "desvastadora", principalmente considerando o cenário da informalidade e precariedade do trabalho no turismo, que de acordo com Meliani $(2012 ; 2015)$ e Santos (2018) prevalece no setor.

Segundo a Associação dos Ambulantes de Ponta Negra (2020), cerca de 380 vendedores ambulantes foram atingidos pela crise em função da paralisação do trabalho, havendo redução significativa de renda. A Associação dos Quiosques de Ponta Negra (2020), com 27 quiosqueiros associados, relatou que, além dos vendedores ambulantes, os mais afetados pelas medidas restritivas de funcionamento do comércio na praia foram os funcionários dos quiosques, que trabalham na informalidade. Em média, são 10 funcionários por quiosque, totalizando cerca de 270 trabalhadores informais entre garçons, cozinheiras, ajudantes de cozinha e entregadores.

Outro grupo fortemente afetado constituiu-se nos trabalhadores autônomos e informais que dependem do fluxo turístico, tais como guias de turismo, bugueiros e condutores de veículos de tração 4 X4. De acordo com o Sindicato dos Bugueiros do Rio Grande do Norte (2020), são cerca de 728 bugueiros que atuam no litoral do estado, sendo a maioria informais, sem cadastro de microempreendedor individual (MEI), o que impossibilitou capitanearem recursos destinados ao socorro a esse tipo de empresa. No grupo de condutores dos veículos $4 \times 4$, que totalizam 34 cooperados, alguns contaram com programa de financiamento do governo estadual para quitarem parcelas de veículos adquiridos. O Sindicato de Guias de Turismo do Rio Grande do Norte, por sua vez, não contou com tais modalidades de apoio. No momento da pesquisa, a entrevistada informou que existem 150 guias de turismo sindicalizados, mas que o estado do Rio Grande do Norte conta com cerca de 600 profissionais registrados.

Os desafios enfrentados pelos trabalhadores do turismo em meio à pandemia são resultado de uma dinâmica de exploração do trabalho (MELIANI, 2012; 2015; SANTOS, 2018; CAÑADA, 2018) intensificada pela crise, que expôs e elevou ainda mais a situação de vulnerabilidade dos trabalhadores.

Para enfrentamento da crise, os trabalhadores contaram com diferentes estratégias, tais como aquisição de cestas básicas doadas pelas prefeituras municipais, governo do estado, proprietários de restaurantes, hoteleiros e sociedade civil, geralmente intermediadas e/ou organizadas pelas entidades representativas. Os mais beneficiados foram os ambulantes e os trabalhadores informais dos quiosques, ou seja, os auxílios foram direcionados para os que se encontravam em condições mais vulneráveis, mas também guias de turismo e bugueiros recorreram a esse auxílio. O Sindbuggy-RN forneceu, inclusive, equipamentos de proteção individual e medicamentos. Além disso, foi criada a campanha RN+Unido (figura 3), uma ação social do governo do RN destinada à arrecadação de alimentos para os trabalhadores do turismo potiguar em situação de vulnerabilidade social em decorrência da paralisação econômica do setor no período de crise da Covid-19. 
Figura 9. Campanha de RN+Unido. Fonte: Portal G1 RN, 2020a.

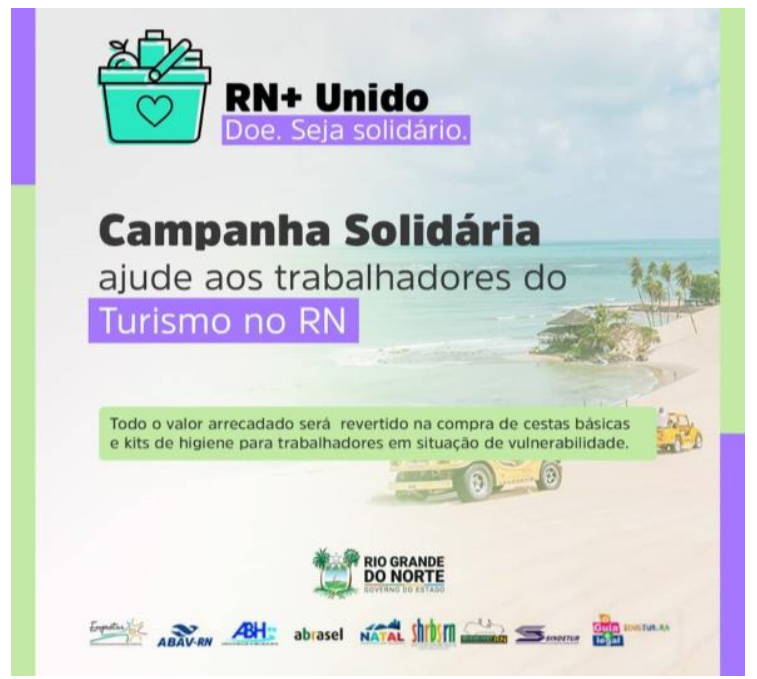

Porém, dentre todas as medidas, segundo relatos dos entrevistados, o auxílio emergencial do governo federal consistiu na principal forma de superar as dificuldades advindas da crise, visto que a maioria dos trabalhadores foi contemplada. Na tabela 2, é possível constatar a grande cobertura que o auxílio emergencial teve nos três municípios em estudo. Tibau do Sul chegou a ter $57,4 \%$ de sua população total beneficiada, São Miguel do Gostoso 51,5\% e Natal 34,3\%, com um valor total médio por favorecido acima de R\$ 2,6 mil, nos 5 meses de auxílio. O auxílio emergencial do governo federal se mostrou essencial para que muitos trabalhadores não ficassem numa situação muito mais crítica diante da crise.

Tabela 2. Cobertura do Programa Auxílio Emergencial do Governo Federal na População de Natal, Tibau do Sul e São Miguel do Gostoso (2020). Fonte: Brasil, Portal da Transparência, Benefícios ao Cidadão, 2020. Organizados pelas autoras (2020).

\begin{tabular}{|c|c|c|c|c|c|c|}
\hline Mun. & Mês/2020 & $\begin{array}{c}\text { Valor } \\
\text { disponibilizado }\end{array}$ & $\begin{array}{c}\text { Pessoas } \\
\text { beneficiadas }\end{array}$ & $\begin{array}{c}\text { Total de } \\
\text { beneficiários }\end{array}$ & $\begin{array}{c}\text { Percentual da } \\
\text { população } \\
\text { beneficiada }\end{array}$ & $\begin{array}{l}\text { Média por } \\
\text { favorecido }\end{array}$ \\
\hline \multirow{6}{*}{ Natal } & abril & $\mathrm{R} \$ 144.579 .600,00$ & 196.048 & \multirow{6}{*}{275.650} & \multirow{6}{*}{$34,3 \%$} & \multirow{6}{*}{$\mathrm{R} \$ 2.738,82$} \\
\hline & maio & $\mathrm{R} \$ 173.707 .800,00$ & 237.427 & & & \\
\hline & junho & $\mathrm{R} \$ 108.567 .600,00$ & 144.411 & & & \\
\hline & julho & $\mathrm{R} \$ 179.166 .600,00$ & 249.011 & & & \\
\hline & agosto & $\mathrm{R} \$ 148.934 .400,00$ & 201.977 & & & \\
\hline & Total & $\mathrm{R} \$ 754.956 .000,00$ & & & & \\
\hline \multirow{6}{*}{$\begin{array}{l}\text { Tibau } \\
\text { do Sul }\end{array}$} & abril & $R \$ 3.316 .200,00$ & 4.690 & \multirow{6}{*}{6.535} & \multirow{6}{*}{$57,4 \%$} & \multirow{6}{*}{$\mathrm{R} \$ 2.659,37$} \\
\hline & maio & $R \$ 3.919 .800,00$ & 5.532 & & & \\
\hline & junho & $R \$ 2.605 .800,00$ & 3.631 & & & \\
\hline & julho & $R \$ 4.059 .000,00$ & 5.823 & & & \\
\hline & agosto & $R \$ 3.478 .200,00$ & 4.943 & & & \\
\hline & Total & $\mathrm{R} \$ 17.379 .000,00$ & & & & \\
\hline \multirow{4}{*}{$\begin{array}{l}\text { São } \\
\text { Miguel } \\
\text { do }\end{array}$} & abril & $R \$ 2.565 .000,00$ & 3.815 & \multirow{6}{*}{4.462} & \multirow{6}{*}{$51,5 \%$} & \multirow{6}{*}{$\mathrm{R} \$ 2.807,98$} \\
\hline & maio & $R \$ 2.763 .000,00$ & 4.093 & & & \\
\hline & junho & $R \$ 2.003 .400,00$ & 2.954 & & & \\
\hline & julho & $R \$ 2.756 .400,00$ & 4.113 & & & \\
\hline \multirow[t]{2}{*}{ Gostoso } & agosto & $\mathrm{R} \$ 2.441 .400,00$ & 3.617 & & & \\
\hline & Total & $\mathrm{R} \$ 12.529 .200,00$ & & & & \\
\hline
\end{tabular}


A realização de outras atividades/funções também foi uma alternativa de muitos trabalhadores do turismo, tais como: venda de bolos, espetinhos e quentinhas; delivery; atuação como motorista Uber; e fabricação de produtos de limpeza.

Os grupos mais organizados foram os mais estratégicos. O Sindbuggy-RN, por exemplo, aderiu ao projeto "Nota Potiguar" (cuja iniciativa se deu pela Secretaria de Turismo do RN e a Secretaria de Tributação do RN) como forma de criar um nicho de mercado, com foco no público potiguar. A Cooperativa $4 \times 4$ abriu uma loja para vender passeios, procurando se diferenciar dos "passeios piratas" e se posicionar melhor no mercado, ressaltando a segurança dos passeios realizados.

Muitos trabalhadores desses dois grupos afirmaram que por causa da boa temporada pela qual passaram em dezembro de 2019 e janeiro de 2020 contavam com reservas financeiras que auxiliaram no enfrentamento da crise. O que não foi o caso de muitos vendedores ambulantes que tiveram, inclusive, que migrar para o interior do estado do Rio Grande do Norte, para casa de familiares, uma vez que não tinham como sobreviver custeando aluguel na capital.

O quadro 3 apresenta uma síntese das principais estratégias adotadas pelos trabalhadores informais e autônomos para enfrentamento da pandemia.

Quadro 3. Estratégias de sobrevivência dos trabalhadores informais e autônomos do setor turístico, diante da pandemia de Covid-19. Fonte: Entrevistas com as entidades relacionadas no quadro (2020). Organizado pelas autoras (2021)

\begin{tabular}{|c|c|c|}
\hline Entidades & $\begin{array}{l}\text { Número de } \\
\text { associados/ } \\
\text { cooperados }\end{array}$ & $\begin{array}{l}\text { Estratégias para enfrentamento da crise gerada pela } \\
\text { pandemia de Covid-19 }\end{array}$ \\
\hline $\begin{array}{l}\text { Associação dos } \\
\text { Ambulantes de } \\
\text { Ponta Negra }\end{array}$ & 380 & $\begin{array}{l}\text { - Fornecimento de cestas básicas (Estado e municípios); } \\
\text { - Auxílio emergencial (governo federal); } \\
\text { - Migração de retorno para municípios do interior (familiares). }\end{array}$ \\
\hline $\begin{array}{l}\text { Sindicato dos } \\
\text { Bugueiros do RN } \\
\text { (Sindbuggy-RN) }\end{array}$ & 728 & $\begin{array}{l}\text { - Uso de reservas financeiras; } \\
\text { - Fornecimento de cestas básicas (Estado, município e Sindbuggy-RN); } \\
\text { - Auxílio emergencial apenas para alguns que se enquadravam } \\
\text { (governo federal); } \\
\text { - Adesão ao projeto "Nota Potiguar" (Secretaria de Turismo do RN e a } \\
\text { Secretaria de Tributação do RN). }\end{array}$ \\
\hline $\begin{array}{l}\text { Sindicato dos Guias } \\
\text { de Turismo do RN }\end{array}$ & 150 & $\begin{array}{l}\text { - Fornecimento de cestas básicas (Estado e municípios, proprietários } \\
\text { de restaurantes e hoteleiros); } \\
\text { - Auxílio emergencial (governo federal); } \\
\text { - Assistência financeira familiar; } \\
\text { - Realização de outras atividades/funções (venda de bolos, } \\
\text { espetinhos, quentinhas e delivery, atuação como motorista Uber) }\end{array}$ \\
\hline Cooperativa $4 \times 4$ & 34 & $\begin{array}{l}\text { - Uso de reservas financeiras (alguns cooperados); } \\
\text { - Fornecimento de cestas básicas (Estado e municípios); } \\
\text { - Auxílio emergencial apenas para alguns que se enquadravam } \\
\text { (governo federal); } \\
\text { - Adesão a programas de financiamento (AGN-Governo estadual) } \\
\text { - Realização de outras atividades/funções (mudanças, fabricação de } \\
\text { produtos de limpeza, venda de açaí); } \\
\text { - Diminuição dos valores dos passeios; }\end{array}$ \\
\hline
\end{tabular}




\begin{tabular}{|l|l|l|}
\hline & $\begin{array}{l}\text { - Abertura de uma loja em Ponta Negra para vender passeios } \\
\text { formais/legais; } \\
\text { - Reposicionamento no mercado para combater concorrência desleal } \\
\text { (passeios piratas/ informais); } \\
\text { - Melhorou a higienização do veículo. }\end{array}$ \\
\hline
\end{tabular}

A formação de redes de solidariedade, envolvendo sindicatos, associações, órgãos públicos e a sociedade civil frente às dificuldades enfrentadas, foi ressaltada por vários entrevistados.

O representante da Cooperativa $4 \times 4$ relatou que desenvolveu algumas ações para auxiliar não só os cooperados, mas também muitos trabalhadores que estavam envolvidos nos passeios que realizavam:

a gente recebeu cesta básica e distribuía por onde a gente passava, a gente sabia que o vendedor da cocada não estava vendendo cocada, o carinha que aluga o caiaque não estava mais alugando e a gente sabia da real situação daquelas pessoas que conviveram com a gente (...) a gente juntou esse esforço de uma campanha arrecadando alimento se juntou com o esforço da prefeitura que era uma cesta básica e dos guias que também recolheu algumas cestas básicas nos doou e a gente saiu distribuindo para aquelas pessoas que estavam no nosso meio social no nosso convívio do turismo, não só os cooperados, mas também aquelas pessoas que dependiam $100 \%$ do nosso fluxo, do nosso passeio.

Tal fato denotou a capacidade de união entre os trabalhadores, sindicatos, órgãos públicos e a sociedade civil. Além disso, promoveu o fortalecimento das entidades representativas dos trabalhadores, para o enfretamento da crise e melhorias para os sindicalizados. Nesse sentido, é interessante destacar a fala do Sindicato dos Bugueiros do RN:

\begin{abstract}
Houve uma rede de solidariedade entre os próprios bugueiros em ceder suas cestas para os bugueiros mais necessitados que não residia em Natal. Recentemente nós assinamos um plano de seguro de vida, odontológico para nós bugueiros. Agora estamos dando um caráter mais profissional a atividade porque antes o sindicato em si era fictício, não era muito participativo. [...]. Primeiras ações são que todos se regularizem na sua documentação. Estamos procurando estímulos para isso, então a gente está tentando a profissionalização de turismo ao máximo através de eles terem MEI, o Nota Potiguar é um caminho. Estamos agora em negociação com o governo do Estado para renovação da frota, uma linha de crédito. Então essa é nossa linha de ação atual.
\end{abstract}

Por fim, os entrevistados relatam as medidas para retomada do turismo no estado potiguar com a realização de cursos de biossegurança ofertados pelo Sebrae no período do isolamento social, a preocupação com medidas protetivas e com a higienização.

\title{
CONSIDERAÇÕES FINAIS
}

A partir dos resultados apresentados do setor de turismo dos três principais destinos do estado do Rio Grande do Norte, conclui-se que o ano de 2020 pode ser dividido em dois diferentes momentos.

O primeiro momento abarca o 1 o semestre de 2020, período em que ocorreu o acirramento das medidas restritivas de funcionamento do comércio e serviços, bem como a queda vertiginosa dos fluxos 
aéreos. Esse período foi marcado pelas altas taxas de desemprego, em especial nos hotéis e restaurantes e similares em Natal, Tibau do Sul e São Miguel do Gostoso. O porte das empresas de turismo dos três destinos, em sua grande maioria, é microempresa, as quais não tiveram condições de manter seus funcionários empregados no auge da crise, tendo em vista a situação de maior vulnerabilidade econômica desse perfil de empresas.

Nesse mesmo período, os trabalhadores autônomos e informais do turismo encontraram-se em uma situação crítica, pois sua principal fonte de renda foi suprimida por cinco meses consecutivos. Guias de turismo, bugueiros, garçons, cozinheiros de quiosques, vendedores ambulantes das praias, entre outros, ficaram completamente sem renda, fruto do seu trabalho, e, dessa forma, tornaram-se dependentes da ajuda familiar e de ações beneficentes organizadas pelas entidades representativas dos trabalhadores, pelos órgãos governamentais e pela sociedade civil. Essas ações envolveram, sobretudo, a distribuição de cestas básicas e de medicamentos. Além disso, os que puderam, iniciaram outras atividades informais, tais como: trabalho como motorista Uber, entregador de refeições (delivery), fornecedor de quentinhas e produção de produtos de limpeza; elevando os índices de trabalho informal e precário no Brasil. Porém, o que de fato possibilitou os trabalhadores autônomos e informais a enfrentarem o período mais acirrado da crise, foi o programa de auxílio emergencial do governo federal, que teve grande abrangência nos municípios em estudo.

As redes de solidariedade e as políticas de seguridade social se mostraram, portanto, essenciais num momento de crise aguda, como a vivenciada em 2020. A crise também induziu a união dos trabalhadores entorno das entidades representativas de classe, revalorizando essas entidades e suas funções.

O segundo momento se refere à retomada dos fluxos turísticos, ainda em tempos de pandemia, a partir de julho de 2020, com o afrouxamento das medidas restritivas. No início, nos meses de julho e agosto, o fluxo turístico era composto basicamente do turismo regional rodoviário, e aos poucos cresce o fluxo aéreo, retomando o turismo nacional. Cabe registrar que o turismo internacional não retornou no ano de 2020.

No segundo semestre de 2020 , as empresas de turismo voltam a contratar, gerando saldos positivos entre demissão e admissão de agosto a dezembro; no caso de Tibau do Sul e São Miguel do Gostoso, o ano de 2020 finaliza com um saldo de empregos maior que do ano de 2019. Em Natal, apesar da retomada do turismo, o número de empregos formais fecha o ano de 2020 com saldo negativo comparado ao ano de 2019, com perdas significativas, em termos relativos, nos empregos de meios de hospedagem e de agências de viagens.

Os trabalhadores informais e autônomos, nesse segundo momento, retornam as suas atividades, seguindo protocolos de segurança para proporcionar maior confiança nos turistas, mas permanecem preocupados com o impacto que a pandemia pode ainda vir a gerar para o setor, visto que o cenário 
pandêmico se mantém, e o Brasil tem registrado recordes de morte/diária por Covid-19, no primeiro trimestre de 2021.

\section{REFERÊNCIAS}

AGÊNCIA NACIONAL DE AVIAÇÃO CIVIL. Base de dados estatísticos do transporte aéreo. Anac, 2020. Disponível em: https://www.anac.gov.br/assuntos/setor-regulado/empresas/envio-de-informacoes/microdados. Acesso em: 3 set. 2020.

ALVES, José Eustáquio Diniz. O impacto mortal da Covid-19 sobre a economia e a demografia brasileira. Portal das Ciências Sociais Brasileiras, Anpocs, Boletim, n. 37, mai.2020. Disponível em: <http://anpocs.org/index.php/publicacoes-sp-2056165036/boletimcientistas-sociais/2351-boletim-n-37-cientistas-sociais-e-o-coronavirus?idU=3>. Acesso em: 27 mai. 2020.

BARRETTO, Margarita. O vírus da desídia. Cenário, Brasília, v. 8, n. 14, p. 1-5, jun. 2020.

BENI, Mario Carlos. Turismo e Covid-19: algumas reflexões. Rosa dos ventos: Turismo e Hospitalidade, Caxias do Sul, v. 3, n. 12, p. 123, jul. 2020.

BRASIL. Ministério da Economia. Secretaria Especial de Previdência e Trabalho. Relação Anual de Informações Sociais - Rais. Base de dados online. 2019. Disponível em: http://bi.mte.gov.br/bgcaged/rais.php. Acesso em: 15 fev. 2021.

BRASIL. Ministério da Economia. Secretaria Especial de Previdência e Trabalho. Novo Cadastro Geral de Empregados e Desempregados - Novo Caged. Base de dados online. 2020. Disponível em: https://app.powerbi.com/view?r=eyJrljoiNWI5NWI0ODEtYmZiYy00Mjg3LTkzNWUtY2UyYjIwMDE1YWI2liwidCI6ljNIYzkyOTY5LTVhNT EtNGYXOC04YWM5LWVmOThmYmFmYTk30CJ9. Acesso em: 15 fev. 2021.

BRASIL. Ministério do Turismo. Categorização dos municípios turísticos - 2019. MTur, 2019a. Disponível em: http://turismo.gov.br/dadosabertos/categorizacao/RELATORIO CATEGORIZACAO 2019-Portal.xls. Acesso em: 5 out. 2020.

BRASIL. Ministério do Turismo. Pesquisa de sondagem empresarial - 2019: empresários do setor de agências e organização de viagens no Brasil 2o semestre de 2019. MTur, 2019b. Disponível em:

http://dadosefatos.turismo.gov.br/component/k2/itemlist/category/17.html. Acesso em: 5 out. 2020.

BRASIL. Ministério do Turismo. Pesquisa de sondagem empresarial - 2020: empresários do setor de agências e organização de viagens no Brasil 2o semestre de 2020. MTur, 2020a. Disponível em:

http://www.dadosefatos.turismo.gov.br/component/k2/itemlist/category/17.html. Acesso em: 24 fev. 2021.

BRASIL. Ministério do Turismo. Relatório de impacto da pandemia de Covid-19 nos setores de turismo e cultura no Brasil. $2020 \mathrm{~b}$. Disponível em: <http://www.dadosefatos.turismo.gov.br/boletins.html>. Acesso em: 24 fev. 2021.

BRASIL. Portal da transparência: benefícios ao cidadão. 2020. Disponível em: http://www.portaltransparencia.gov.br/beneficios. Acesso em: 10 de dezembro de 2020.

CAÑADA, Ernest. Trabajo turístico y precariedad. In: CAÑADA, Ernest; MURRAY, Ivan. Turistificación global. Perspectivas críticas en turismo. Barcelona: Icaria Editorial, 2019, p. 267-287.

CRUZ, Rita de Cássia Ariza da. Praias lotadas no feriado: o grito de independência de turistas pelo mundo e no Brasil. Le Monde Diplomatique Brasil, 14 set. 2020. Disponível em: < https://diplomatique.org.br/o-grito-de-independencia-de-turistas-pelo-mundoe-no-brasil/>. Acesso em: 24 mar. 2020.

G1. Um terço da população mundial está em isolamento; veja medidas de diferentes países para conter o coronavírus. 27 mar. 2020. Disponível em: <https://g1.globo.com/bemestar/coronavirus/noticia/2020/03/27/13-da-populacao-mundial-esta-emisolamento-veja-medidas-de-diferentes-paises-para-conter-o-coronavirus.ghtml>. Acesso em: 26 mai. 2020.

G1 RN. Governo do RN cria campanha de doação de alimentos para famílias de baixa renda durante isolamento do coronavírus. 13 abr. 2020. 2020a. Disponível em: https://g1.globo.com/rn/rio-grande-do-norte/noticia/2020/04/13/governo-do-rn-criacampanha-de-doacao-de-alimentos-para-familias-de-baixa-renda-durante-isolamento-do-coronavirus.ghtml. Acesso em: 26 mai. 2020.

G1 RN. Turistas se aglomeram sem máscaras na praia da Pipa durante feriadão. 7 set. 2020. 2020b. Disponível em: https://g1.globo.com/rn/rio-grande-do-norte/noticia/2020/09/07/turistas-se-aglomeram-sem-mascaras-na-praia-da-pipa-duranteferiadao.ghtml. Acesso em: 10 set. 2020. 
HARVEY, David. A política anticapitalista na época da Covid-19. 2020. Disponível em: <http://www.ihu.unisinos.br/78noticias/597468-a-politica-anticapitalista-na-epoca-da-covid-19-artigo-de-david-harvey>. Acesso em: 26 mai. 2020.

INSTITUTO BRASILEIRO DE GEOGRAFIA E ESTATÍSTICA. Cidades: população estimada 2020. IBGE, 2010. Disponível em: https://cidades.ibge.gov.br/. Acesso em: 1 out. 2020.

INSTITUTO BRASILEIRO DE GEOGRAFIA E ESTATÍSTICA. Cidades: produto interno bruto dos municípios. IBGE, 2018. Disponível em: https://cidades.ibge.gov.br/. Acesso em: 1 out. 2020.

IPEA. Dimensão da ocupação do turismo. 2019. Disponível em: http://extrator.ipea.gov.br/. Acesso em: 21 fev. 2021.

KRAEMER; Moritz U. G. et. al. The effect of human mobility and control measures on the Covid-19 epidemic in China. Science, 25 mar. 2020. Disponível em: <https://science.sciencemag.org/content/368/6490/493>. Acesso em: 27 mai. 2020.

MECCA, Marlei Salete; GEDOZ, Maria Gorete do Amaral. Covid-19: reflexos no turismo. Rosa dos ventos: turismo e hospitalidade, Caxias do Sul, v. 3, n. 12, p. 1-5, jul. 2020.

MELIANI, Paulo Fernando. Estrutura e distribuição espacial do trabalho formal e informal no turismo do Brasil: contributos geográficos ao planejamento turístico regional brasileiro. Revista turismo e desenvolvimento, Aveiro, v. 17, n. 1, p. 467-478, jun. 2012.

MELIANI, Paulo Fernando. Pensando o trabalho no turismo: sobre servilismo e precarização das relações trabalhistas na prestação de serviços turísticos. Especiaria - cadernos de ciências humanas, Ilhéus, v. 14, n. 26, p. 95-117, jun. 2015.

ONU NEWS. Pandemia transforma 2020 no pior ano para o setor de turismo internacional. 21 dez. 2020. 2020b. Disponível em: <https://news.un.org/pt/story/2020/12/1736672>. Acesso em: 24 fev. 2021.

ONU NEWS. Restrições de viagem afetam 96\% de todos os destinos mundiais. 18 abr. 2020. 2020a. Disponível em: <https://news.un.org/pt/story/2020/04/1710682>. Acesso em: 27 mai. 2020.

SANTOS, Luís Eduardo de Freitas. Trabalho no turismo: faces da precarização de um proletariado contemporâneo e de serviços. Dissertação (Mestrado em Geografia Humana) - Universidade de São Paulo, São Paulo, 2018.

SCHMIDT, Flávia; MELLO, Janine; CAVALCANTE, Pedro. Estratégias de coordenação governamental na crise da Covid-19. Ipea. Nota Técnica. Diretoria de Estudos e Políticas do Estado, das Instituições e da Democracia, n. 32, abr. 2020.

SEBRAE. DataSebrae. Painel de empresas. 2020. Disponível em: <https://datasebrae.com.br/totaldeempresas/>. Acesso em: 20 ago. 2020.

TOPPER, Benjamin; LAGADEC, Patrick. Fractal crises - a new path for crisis theory and management. Journal of contingencies and crisis management, v. 21, n. 1, p. 4-16, mar. 2013.

VALOR. 49,9 mil estabelecimentos de turismo fecharam as portas na pandemia, aponta CNC. 5 out. 2020. Disponível em: <https://valor.globo.com/brasil/noticia/2020/10/05/499-mil-estabelecimentos-de-turismo-fecharam-as-portas-na-pandemiaaponta-cnc.ghtml>. Acesso em: 24 fev. 2021.

WHO. WORLD HEALTH ORGANIZATION. Report of the WHO-China joint mission on coronavirus disease 2019 (Covid-19). 16-24 February 2020. 2020b. Disponível em: <https://www.who.int/docs/default-source/coronaviruse/who-china-joint-mission-on-covid19-final-report.pdf>. Acesso em: 27 mai. 2020.

WTTC. Brazil 2020 annual research: key highlights. 2020a. Disponível em: <https://wttc.org/Research/Economic-Impact>. Acesso em: 20 ago. 2020.

WTTC. Economic impact reports. 2020b. Disponível em: <https://wttc.org/Research/Economic-Impact>. Acesso em: 20 ago. 2020. 